34

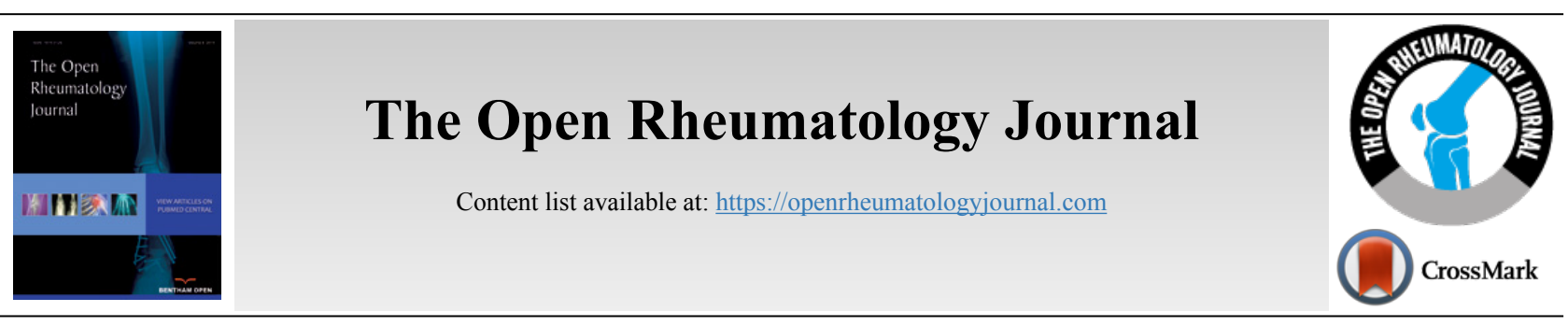

RESEARCH ARTICLE

\title{
Oral Mucosal Lesions and DMFT Index Assessment in Rheumatoid Arthritis Patients in Birjand, Iran, in 2018
}

\author{
Parvin Parvaei ${ }^{1}$, Afsaneh Dorri-giv ${ }^{1}$, Gholamreza Sharifzadeh ${ }^{1}$, Hakimeh Malakimoghadam $^{1}$ and Elham Atabati $1^{1, *}$ \\ ${ }^{\prime}$ Department of Oral Medicine, School of Dentistry, Birjand University of Medical Sciences, Birjand, Iran \\ ${ }^{2}$ Birjand University of Medical Sciences, Birjand, Iran \\ ${ }^{3}$ Social Determinants of Health Research Center, Birjand University of Medical Sciences, Birjand, Iran \\ ${ }^{4}$ Clinical Research Development Unit, Birjand University of Medical Sciences, Birjand, Iran \\ ${ }^{5}$ Birjand University of Medical Sciences, Birjand, Iran
}

\begin{abstract}
:
Introduction:

Rheumatoid Arthritis (RA) may cause malfunction in the immune system and the inability to observe oral hygiene in patients due to physical deficits. A bacterial infection caused as such can constitute a significant risk factor for the development of systemic infection. The present study aimed to investigate the oral mucosal lesions, the DMFT index, and the Modified Gingival Index (MGI) in RA patients treated in Birjand city.

\section{Materials and Methods:}

This descriptive cross-sectional study was performed with 80 RA patients referred to rheumatology clinics of Birjand in 2018. Data were collected through observation, clinical examination, information forms, and medical records. After the patients were informed about the research purposes and signed consent forms for participation, they were examined at the rheumatology clinics. The collected data were analyzed in SPSS software (version 19).

Results:

Of the 80 patients, $n=64(80 \%)$ had oral mucosal lesions. Dry mouth $(66.3 \%)$ was the most common finding. The mean DMFT index score was 18.7 .

Conclusion:

Oral mucosal lesions and the mean DMFT index score seem to be at high levels in RA patients, possibly due to the complications of the disease or the consumed medications.
\end{abstract}

Keywords: Rheumatoid arthritis, Oral mucosal lesions, DMFT, Modified gingival index, RA patients, Dry mouth.

\begin{tabular}{|l|l|l|l|}
\hline Article History & Received: March 10, 2020 & Revised: August 21, 2020 & Accepted: September 30, 2020
\end{tabular}

\section{INTRODUCTION}

The World Health Organization (WHO) considers oral health as a vital part of life-long general health, maintaining that poor oral health and untreated oral diseases can have a profound effect on the quality of life. In fact, some chronic diseases are related to oral problems. Therefore, a WHO program concerning chronic disease prevention and health promotion has centered on oral health [1].

Thousands of people worldwide suffer from periodontal

\footnotetext{
* Address correspondence to this author at the Birjand University of Medical Sciences, Birjand, Iran;

E-mail: elham1405@yahoo.com
}

diseases, the prevalence of which is high, even exceeding that of dental caries [2]. Periodontal diseases are of different types but with one common pathology: they alter the ideal conditions of the periodontium and provide the context for dental caries. Periodontal diseases are the leading cause of permanent tooth loss. Inflammation, bleeding, gum disease, bone resorption, tooth mobility, pain, and many other complications follow periodontal diseases [3].

Based on research on the relationship between periodontitis and systemic diseases, a link has been reported between the prevalence of periodontal diseases and Rheumatoid Arthritis (RA), heart disease, and diabetes 
mellitus. Numerous similar cases have also been found in the pathobiology of periodontitis and RA [4].

RA is an autoimmune disease that is often mild to chronic, although it can also be severe and paralyzing. The disease is a global phenomenon, affecting approximately one percent of the world's population, with a three-fold chance of incidence in women. The incidence is highest in the fourth and fifth decades of life. Three percent of the American population grows some degree of the disease, and some 200,000 new cases are diagnosed annually [5]. The disease affects joints symmetrically, especially moving organs. In most patients, limb deformities and reduced organ function are reported. The role of immunity has been confirmed in this disease as well as periodontitis [6].

Stomatitis is a problematic side effect of treatment with disease-modifying anti-rheumatoid drugs in RA patients [7, 8]. After examining the toxicity profiles of anti-rheumatoid drugs, Singh et al. reported that the highest rate of mucosal ulcers was caused by methotrexate, followed by oral gold, intramuscular gold, diphenylamine, azathioprine, and hydroxychloroquine [9]. Long-term use of methotrexate and other anti-rheumatic drugs, such as D-penicillamine and NSAIDs, can lead to stomatitis, while cyclosporine can cause gingival hyperplasia, i.e., the overgrowth of the gums. Direct effects of the disease can also be found in the oral cavity. In patients with persistently active RA, periodontal disease has been reported, including alveolar bone resorption and tooth loss. Sjögren's syndrome also presents the most common comorbidity associated with RA. Temporomandibular joint (TMJ) involvement may also be the case $[10,11]$.

Nearly 30 percent of RA patients may develop secondary Sjögren's syndrome, which is a type of autoimmune exocrinopathy [12]. Under such conditions, the patient may have increased chances of periodontal complications due to reduced salivary secretion, dryness of the oral mucosa, and, subsequently, the decreased antibacterial effects of saliva [13]. TMJ involvement has been reported in 1 to 60 percent of these patients, where the significant difference may attributable to the use of different criteria to determine the TMJ disorder [14, $15]$.

Oral lesions are one of the most critical side effects of autoimmune diseases. Ulcer, petechiae, telangiectasia, and lichenoid lesions are the most common presentations of oral mucosal involvement. Interestingly, the drugs used to treat these systemic diseases can produce similar side effects [16]. Erosion, ulceration, cheilitis, oral candidiasis, lichen-like lesions, leukoplakia, and persistent oral dryness are more frequent in RA patients [17]. In 50 percent of patients, the persistent disease can lead to disability [18].

TMJ involvement and its impact on chewing ability, the inability of upper extremities that affects brushing, the use of oral medications containing sugar, and disregard for dental health in these patients are contributors to increased risk of caries.

These patients need to control oral hygiene because inappropriate oral hygiene can lead to dental caries and periodontal diseases. Bacterial infections caused by these diseases, in turn, constitute a significant risk factor for systemic infection. This is especially the case in these patients whose immune system is weakened due to the use of immunosuppressive drugs, such as corticosteroids, as well as anti-rheumatic drugs, such as methotrexate [19].

Taking into account the above-mentioned factors and the lack of comprehensive statistical data in the context of Iran, the present study aimed to determine the prevalence of oral mucosal lesions, DMFT, and Modified Gingival Indices (MGI) in RA patients treated in Birjand city.

\section{METHODS}

The population in this cross-sectional study consisted of RA patients referred to the rheumatology clinics of Birjand in 2018. All the patients with known RA whose disease was diagnosed in the rheumatology clinic of Valiasr Hospital ( $\mathrm{n}=$ 80) were selected via a convenience sampling method.

Eighteen-year-old or older patients who had a one-year or longer history of RA diagnosis according to ACR-EULUR criteria and a disease activity score between 1.5 and 2.3 were included. Patients were excluded if they had other systemic diseases such as leukemia, diabetes, white blood cell deficiency, anemia, kidney and liver disease, and AIDS. They were excluded, too, if they used tobacco or drugs that affected the histological features of the gums such as nifedipine and corticosteroids and if they had consumed antibiotics during the past three months. The purpose of the study was explained to the participants, and they signed written consent forms for participation. Patients were examined and advised for free. All the obtained information was recorded confidentially, and only anonymous information was used in the report. The study protocol was approved by the Ethics Committee of Birjand University of Medical Sciences (Identifier:Ir.bums. REC. 1398.032).

The data were collected through observation, clinical examination, information forms, and medical records. The researcher referred to rheumatology clinics across Birjand and explained the objectives of the study to the patients. In case they agreed to participate in the study, they signed consent forms and were examined. Individual and social characteristics were surveyed and recorded in an information form. Age, sex, smoking status, DMFT index, MGI and duration of RA were recorded.

DMFT is an indicator that denotes the total number of teeth or surfaces that are Decayed (D), Missing (M), or Filled (F) in an individual. MGI is the index of gingivitis, which assesses the four surfaces (facial, lingual, mesial and distal) of teeth. MGI scores range from 0 to 4 , as follows:

Score 0: Healthy gums.

Score 1: Mild inflammation with slight changes in the color and consistency of the gums in each part of the gums but not in the entire margin and interdental papilla.

Score 2: Mild inflammation involving the entire margin and interdental papilla.

Score 3: Moderate inflammation in the form of gloss, redness, edema, and hypertrophy of the margins and interdental papilla.

Score 4: Severe inflammation, marked redness, edema, and hypertrophy of the margins and interdental papilla along with spontaneous bleeding, congestion, and ulceration of the gums. 
Oral examination was initiated from the surface of the vermilion border of the lips using a flashlight and a mirror. To this end, internal surfaces of the lips, cheek mucosa, vestibule, alveolar mucosa, gingiva, dorsal surface, tongue base, ventral part of the tongue, lateral tongue borders, oral palate, and hard and soft palate were examined for mucosal changes. Dry mouth was assessed based on physical observation and salivary secretion studies were performed according to the criteria of the American College of Rheumatology. The diagnosis of dry mouth in patients was made using a positive tongue blade mark. A positive tongue blade mark occurs when a tongue depressor, which is gently pressed into the mucosa of the tongue or buccal mucosa, sticks to the mucosa; otherwise, the tongue blade mark is negative and the person lacks a dry mouth.

The data were analyzed in SPSS software (version 19) using descriptive statistical tests, including chi-square, independent t-test, analysis of variance, Tukey's post hoc test, and Pearson's correlation coefficient. If the DMFT index and MGI did not have a normal distribution, the Mann-Whitney test, Kruskal-Wallis test, and Spearman correlation coefficient were used. The significant level was set at $\alpha=0.05$.

\section{RESULTS}

Most of the participants were female (90\%) and illiterate $(32.5 \%)$ and ranged in age from 40 to 60 years $(57.5 \%)$. The majority used corticosteroids and cytotoxic drugs (47.5\%). Moreover, most of them $(38.8 \%)$ had RA for three years or less. Exophytic lesions had the lowest prevalence (1.3\%), while dry mouth had the highest prevalence (66.3\%) (Table 1).

Table 1. Prevalence of oral mucosal lesions in the participants.

\begin{tabular}{|l|c|c|c|c|}
\hline \multicolumn{1}{|c|}{ Status / Lesion } & \multicolumn{2}{c|}{ Positive } & \multicolumn{2}{c|}{ Total } \\
\hline \multicolumn{1}{|c|}{ Stomatitis } & 3 & 3.8 & 80 & 100 \\
\hline Candidiasis & 3 & 3.8 & 80 & 100 \\
\hline Gingival hyperplasia & 16 & 20 & 80 & 100 \\
\hline Mucosal pigmentation & 16 & 20 & 80 & 100 \\
\hline Erosion & 3 & 3.8 & 80 & 100 \\
\hline Lichen-like lesions & 3 & 3.8 & 80 & 100 \\
\hline Petechiea & 7 & 8.8 & 80 & 100 \\
\hline Exophytic lesions & 1 & 8.8 & 80 & 100 \\
\hline TMJ involvement & 7 & 8.8 & 80 & 100 \\
\hline Dry mouth & 53 & 66.3 & 80 & 100 \\
\hline
\end{tabular}

Eighty percent of the patients had at least one oral lesion, whereas $20 \%$ had no lesion $(\min =0, \max =5)$. Each patient had, on average, $1.4( \pm)$ oral lesions. The prevalence of lesions was higher in 40- to 60-year-old individuals. However, there was no significant relationship between the prevalence of oral mucosal lesions and age $(\mathrm{P}=0.26)$, sex $(\mathrm{P}=0.65)$, duration of disease $(P=0.5)$, and type of medication used $(P=0.15)$. The prevalence of oral mucosal lesions was education-dependent such that illiterate individuals and those with primary education reported a significantly higher prevalence of oral mucosal lesions $(\mathrm{P}=0.002)$. The mean DMFT index score for the patients was $18.7(\max =32 ; \min =5)$. The mean MGI index score was 1.8 (Table 2 ).
Table 2. Central tendency index and dispersion of MGI and DMFT scores of the participants.

\begin{tabular}{|c|c|c|c|c|c|}
\hline $\begin{array}{c}\text { Statistical } \\
\text { index / } \\
\text { Variable }\end{array}$ & Minimum & Maximum & Mean & $\begin{array}{c}\text { Standard } \\
\text { deviation }\end{array}$ & Median \\
\hline DMFT & 6 & 32 & 18.7 & 6.4 & 18 \\
\hline MGI & 0 & 4 & 1.8 & 0.91 & 2 \\
\hline
\end{tabular}

There was no statistically significant difference in the mean DMFT index concerning sex $(\mathrm{P}=0.13)$ and the type of medication used $(\mathrm{P}=0.7)$. The mean DMFT index was agedependent $(\mathrm{P}=0.002)$, for which the Tukey's post hoc test showed a difference between age groups above 60 and those below 40 years $(P=0.003)$ and between those above 60 and those between 40 to 60 years $(\mathrm{P}=0.006)$. There was also a significant difference in the mean DMFT index by education level $(\mathrm{P}=0.01)$, where Tukey's post hoc test showed a significant difference between illiterate individuals and high school diploma holders $(\mathrm{P}=0.02)$ and between illiterate individuals and tertiary degree holders $(\mathrm{P}=0.03)$. The mean DMFT index score was significantly higher in patients with lesions (Table 3).

Table 3. Comparison of the mean DMFT index scores by oral mucosal lesion status.

\begin{tabular}{|c|c|c|c|}
\hline DMFT / Oral lesion & Frequency & $\mathbf{X} \pm$ SD & T-test result \\
\hline Positive & 64 & $19.5 \pm 6.3$ & $\mathrm{~T}=-2.2$ \\
Negative & 16 & $15.6 \pm 5.9$ & $\mathrm{df}=78$ \\
$\mathrm{P}=0.03$ \\
\hline
\end{tabular}

There was a significant difference in the mean MGI index score in terms of age $(\mathrm{P}=0.006)$, where the Tukey's post hoc test showed that the difference was statistically significant between the age group above 60 years and below 40 years $(\mathrm{P}=$ 0.004). Moreover, the mean MGI index score increased with age.

There was also a significant difference in the mean MGI score by education level $(\mathrm{P}=0.001)$. Tukey's post hoc test revealed that the difference was significant between illiterate and college-educated individuals $(\mathrm{P}=0.002)$ and between those with primary education and those with a university degree $(P=0.006)$. The mean MGI index score was not significantly different as per the type of medication $(\mathrm{P}=0.3)$ and duration of disease $(P=0.9)$. Moreover, there was a significant direct relationship between the mean MGI index score and the status of oral mucosal lesions $(\mathrm{P}=0.002)$ (Table 4).

Estimation of Pearson correlation coefficient between ESR $(\mathrm{P}=0.002)$ and anti-CCP $(\mathrm{P}=0.042)$ variables showed a significant positive relationship with DMFT index.

Table 4. Comparison of the mean MGI index score by oral mucosal lesion status.

\begin{tabular}{|c|c|c|c|}
\hline MGI / Oral lesion & Frequency & $\mathbf{X} \pm$ SD & T-test result \\
\hline Positive & 64 & $0.9 \pm 1.9$ & $\mathrm{~T}=-3.1$ \\
Negative & 16 & $0.8 \pm 1.2$ & $\mathrm{df}=78$ \\
$\mathrm{P}=0.002$ \\
\hline
\end{tabular}


Also, estimation of the correlation coefficient of MGI and quantitative indices in the studied patients revealed a positive and significant relationship between the variables of DAS28 (P $=0.00)$ and $\operatorname{ESR}(P=0.00)$ and the mean score of MGI index as well as an inverse and significant relationship between VIT$\mathrm{D}(\mathrm{P}<0.001)$ and MGI index.

Lastly, a significant reverse relationship was found between vitamin D levels and the prevalence of oral mucosal lesions.

\section{DISCUSSION}

RA is the most common chronic inflammatory disease of the joints, which can lead to joint damage, disability, and movement limitation in patients [20]. On the other hand, oral lesions are one of the significant side effects of autoimmune diseases. Ulcer, petechiae, telangiectasia, and lichenoid lesions are the most common manifestations of oral mucosal involvement. In the meantime, medications used for systemic treatment can cause similar side effects [16]. TMJ involvement and its effect on one's chewing function, the inability of the upper extremities with an impact on brushing, consumption of oral medications containing sugar, and neglect of dental health in these patients are contributors to increased risk of caries [19]. Therefore, this study aimed to evaluate the prevalence of oral mucosal lesions and DMFT index in RA patients.

According to the results of the present study, out of 80 patients, 72 were women. Other studies also report a higher rate of the disease in women [21,22]. Alongside this, Lipsky has mentioned, in Harrison's book, a three-fold incidence rate in women [23].

The current study found that 64 patients $(80 \%)$ had oral mucosal lesions. Among these, dry mouth proved to be the most prevalent complication (66.3\%), and exophytic lesions were least prevalent. Khatibi et al.'s study, which examined oral mucosal lesions in 385 patients, showed that oral lesions had a 40.5 percent prevalence rate and that dry mouth constituted the most common type with a frequency of 13.8 percent [24]. Our results are comparable to those of Geterud et al.'s study (1991), where oral symptoms, especially dry mouth and difficulty in swallowing, were assessed in people with RA, showing that oral lesions were of a 21 percent prevalence rate [25]. In a 2010 study, Pedrazas et al. evaluated the prevalence of oral lesions in 49 RA patients, reporting a $55.1 \%$ prevalence rate. In their study, the most common lesions were ulcerous lesions, candidiasis, gingival hyperplasia, and the enlargement of the parotid gland [26].

In Mays et al.'s 2012 review study of clinical trials, the most common oral mucosal lesions in RA patients were TMJ involvement, periodontitis, dry mouth, enlarged salivary glands, especially the parotid, increased dental caries, and candidiasis [11].

In this study, the prevalence of oral mucosal lesions was substantially higher than in similar studies. This is probably attributable to the setting where the studies have been completed, with some being conducted in more advanced countries that enjoy higher oral hygiene levels and other studies being performed in larger cities where individuals are of a higher socio-economic level than the patients in the present study.

In the present study, the average DMFT index in 80 patients with rheumatoid arthritis was 18.7. Nonetheless, the average DMFT index based on the results of a comprehensive study on oral health in Iran in 2001 was 11 for the 35 to 45year-old age group [27]. The larger population in other studies can also be a contributor to the different statistical figures.

From among the relevant variables examined in this study, age and sex had no significant relationship with the prevalence of oral mucosal lesions, which corresponds with the findings from Aliko et al. (2010), Pedrazas et al. (2010), and Khatibi et al. (2014) [24, 27, 28].

According to the results of this study, the prevalence of oral mucosal lesions was not significantly associated with the duration of the disease and the type of drug used. This finding was not in line with those of Khatibi et al.'s study, where the duration of the disease had a significant association with the frequency of oral mucosal lesions. In fact, the prevalence reduced with age. In Khatibi et al.'s study, moreover, there was a direct relationship between oral mucosal lesions and the use of corticosteroids, NSAIDs, and immunosuppressive drugs. The lack of association between the severity of symptoms and the duration of the disease was due to the small number of patients and the limitation of information.

Based on the results of the present study, the mean DMFT index score was 18.7 for RA patients. Nevertheless, the average DMFT index score in Iran in 2011 was 2.6 [29]. The high DMFT index score in our patients can be attributed to the patients' use of oral medications containing sugar and the nonmaintenance of dental health as well as their upper extremity disability, which affects tooth brushing. This finding was also highlighted in May's 2012 review study, pinpointing that poor oral hygiene in this group of patients was because of their RAinduced impaired manual skills [11].

A significant difference was found in this study in the mean DMFT index score by age $(\mathrm{P}=0.002)$. Tukey's post hoc test showed that the difference was statistically significant between the age groups above 60 years and below 40 years $(\mathrm{P}$ $=0.003)$ and between those above 60 years and those in the $40-60$ years range $(\mathrm{P}=0.006)$. The reason for the higher mean DMFT index score in people over 60 years may be their greater exposure to caries, reduced ability to maintain oral health and fewer referrals to the dentist.

Moreover, according to the results of the present study, there was a significant difference in the mean DMFT index score as per education level $(\mathrm{P}=0.01)$. Tukey's post hoc test showed that the difference was statistically significant between illiterate individuals and high school diploma holders ( $\mathrm{P}=$ $0.02)$ and between the illiterate and tertiary degree holders (0.03). To justify this, one may maintain that increased education level raises one's awareness of oral health; on the other hand, educated people have easier access to preventive services and, therefore, can reach health centers more conveniently.

The present study did not find a significant relationship between the mean DMFT index score, the duration of disease $(\mathrm{P}=0.06)$, and the type of medication used $(\mathrm{P}=0.07)$. No similar study was found to have investigated the relationship between the mean DMFT index score and age, education level, duration of disease, and type of drug used in RA patients.

According to the results of this study, the mean DMFT index score was significantly associated with the oral mucosal 
lesions status ( $\mathrm{P}=0.02)$; in similar lines, the mean MGI index score had a significant association with the status of oral lesions $(\mathrm{P}=0.002)$. The higher prevalence of oral mucosal lesions in patients with higher mean DMFT and MGI scores can be attributed to the patients' disregard for oral hygiene and timely referral for the treatment of oral lesions.

According to the results of this study, there was a significant relationship between the mean DMFT index score and the variables of ESR $(P=0.002)$ and anti-CCP $(P=0.04)$. The correlation between the anti-CCP level and the mean DMFT index score indicates that the higher the severity of the disease and the production of citrulline proteins in the body, the greater the risk of tooth decay and damage, and the higher the DMFT index score. The significant association between DMFT and ESR also supports this.

A significant relationship was found, moreover, between the mean MGI index score and the DAS28 $(\mathrm{P}=0.00)$ and ESR $(\mathrm{P}=0.00)$ levels. The significant relationship between these two variables also indicates that the more active the RA is, the higher the mean MGI index score will be, suggesting that the individual's periodontal tissue is involved to a higher degree.

Taken together, these findings suggest that an active disease (elevated DAS28, anti-CCP, and ESR) increases tooth decay, periodontal tissue involvement, and consequently, tooth loss in RA patients. Studies thus far have not directly referred to this issue, and it can be concluded that more accurate treatment and regular control of the disease to reduce anti-CCP, DAS28, and ESR can prevent dental complications and oral diseases.

Finally, there was a significant reverse relationship between vitamin D level and the mean DMFT $(\mathrm{P}=0.01)$ and MGI $(\mathrm{P}=0.00)$ scores such that the mean DMFT and MGI scores increased as the vitamin D level decreased. Vitamin D is an anti-inflammatory agent involved in blocking the initiation of the inflammation process in all body systems. Therefore, it could be inferred that low vitamin D levels both have a direct effect on the activation of inflammatory pathways and trigger the RA disease, hence, deteriorating oral health indicators. Similar results were obtained in a 2013 study on 1,688 children by Kim et al. According to the results of their study, people with vitamin D levels below $50 \mathrm{nmoh}$ were 1.3 times more likely to have first molar tooth decay than those with higher serum vitamin D levels, which is consistent with the results of the present study [30]. However, the study by Bahramian et al. in 2017 reported that the mean vitamin D serum level in patients with oral lichen planus was not significantly different from that of healthy controls $(\mathrm{P}=0.34)$, which is inconsistent with the results of the present study [31].

\section{CONCLUSION}

In this study, the prevalence of oral mucosal lesions was high. This condition can be improved if people are better educated concerning oral mucosal lesions and are referred to the dentist as soon as possible to receive medical services. Dry mouth $(66.3 \%)$ was the most prevalent lesion in the participants. To improve the dry mouth condition of patients and to assist in swallowing, we may recommend that they be referred to the dentist for appropriate palliative care such as artificial saliva. A significant difference was found between the education level and the prevalence of oral mucosal lesions such that the prevalence of oral mucosal lesions was higher in illiterate individuals than individuals with higher education levels. Provision of more information about oral mucosal lesions, referral of patients by general practitioners and dentists to specialists, and convenient access to treatment centers are effective strategies to improve the health condition of these patients.

To improve the DMFT index score, it can be an effective measure to prioritize the prevention of dental caries of the patients and increase their awareness concerning regular visits to health care providers.

Based on the results of the present study, the mean DMFT index score varied significantly according to age and education level. It would be useful to provide more information about oral health and to make regular appointments for older people in order to improve their health conditions.

\section{SUGGESTIONS}

The results of this study do not represent the whole population. To generalize the results to the whole population, it is necessary to conduct large-scale studies with more samples.

We may suggest investigation and research in other rheumatology centers of the country to compare the findings and increase the generalizability of the results. We also suggest searching for ways that can control and eliminate the problem of oral mucosal lesions in RA patients. In this regard, referring patients to the dentist can help control oral complications.

Finally, the results of this study highlight the importance of considering oral lesions as a possible complication of RA, the use of medications, and the control of patients' oral health.

\section{IMPLICATIONS}

1. Regular follow-ups of these people for prevention purposes.

2. To justify physicians for timely referral.

3. Timely treatment of lesions by the dentist.

\section{ETHICS APPROVAL AND CONSENT TO PARTICIPATE}

The study protocol was approved by the Ethics Committee of Birjand University of Medical Sciences, Birjand, Iran. [Identifier:Ir.bums. REC.1398.032].

\section{HUMAN AND ANIMAL RIGHTS}

No Animals were used in this research. All human research procedures followed were in accordance with the ethical standards of the committee responsible for human experimentation (institutional and national), and with the Helsinki Declaration of 1975, as revised in 2013.

\section{CONSENT FOR PUBLICATION}

Informed written consent was taken from all the patients when they were enrolled. 


\section{AVAILABILITY OF DATA AND MATERIALS}

Not applicable.

\section{FUNDING}

None.

\section{CONFLICT OF INTEREST}

The authors declare no conflict of interest, financial or otherwise.

\section{ACKNOWLEDGEMENTS}

Declared none.

\section{REFERENCES}

[1] Shamsi M, Hidarnia AR, Atarha M, Jadidi R. Oral health of pregnant women in Arak, Iran. Payesh 2013; 12(4): 355-65.

[2] Krishna KB, Raju PK, Chitturi RR, Smitha G, Vijai S, Srinivas BV. Prevalence of gingival enlargement in Karnataka school going children. J Int Oral Health 2014; 6(1): 106-10. [PMID: 24653613]

[3] Anegundi RT, Sudha P, Nayak UA, Peter J. Idiopathic gingival fibromatosis: A case report. Hong Kong Dent J 2006; 3(1): 53-7.

[4] Schmitz M. Disease activity and fanctinal status thresholds according to the Pationts Acceptable Symptom State [PASS] of rheumathoid arthritis Brazilian pationtsarthritis and rheumatism 2008; 2(3): 86-92.

[5] Gleissner C, Willershausen B, Kaesser U, Bolton W. The role of risk factors for periodontal disease in patients with rheumathoid arthritis. Eur J Med Res 1998; 3(8): 387-92.

[6] Bakhtiari S, Taheri J, Abbasi F. Association between rheumatoid arthritis and moderate to severe periodontitis in Iranian adults. J Dent Tehran Uni Med Sci 2009; 6(3): 145-9.

[7] Carpenter EH, Plant MJ, Hassell AB, et al. Management of oral complications of disease-modifying drugs in rheumatoid arthritis. Br J Rheumatol 1997; 36(4): 473-8.

[http://dx.doi.org/10.1093/rheumatology/36.4.473] [PMID: 9159543]

[8] Kalantzis A, Marshman Z, Falconer DT, Morgan PR, Odell EW. Oral effects of low-dose methotrexate treatment. Oral Surg Oral Med Oral Pathol Oral Radiol Endod 2005; 100(1): 52-62. [http://dx.doi.org/10.1016/j.tripleo.2004.08.020] [PMID: 15953917]

[9] Singh G, Fries JF, Williams CA, Zatarain E, Spitz P, Bloch DA. Toxicity profiles of disease modifying antirheumatic drugs in rheumatoid arthritis. J Rheumatol 1991; 18(2): 188-94. [PMID: 1673721]

[10] Greenberg MS, Glick M, Ship JA. Burket's Oral Medicine. $11^{\text {th }}$ ed. BC Decker Inc. 2008; p. 454.

[11] Mays JW, Sarmadi M, Moutsopoulos NM. Oral manifestations of systemic autoimmune and inflammatory diseases: Diagnosis and clinical management. J Evid Based Dent Pract 2012; 12 (3 (Suppl.)): 265-82.

[http://dx.doi.org/10.1016/S1532-3382(12)70051-9] [PMID: 23040353]

[12] Carsons S. Sjogren's Syndrome in Kelley's Textbook of Rheumatology. 2008.

[13] Taheri M, Saghafi M. Najafi, Mohammad Hasan, Radvar, Mehrdad, Marjani, Sedighe, Javanbakht, Aida, Baghani, Zahra. Investigation of Periodontal Conditions in Patients with Rheumatoid Arthritis. Journal of Mashhad Dental School 2011; 35(4): 283-8.

[14] Behzare A. Prevalence of oral and jaw problems in patients with rheumatoid arthritis. Doctorate Thesis. Iran: Dental School of Mashhad University of Medical Sciences 1992.

[15] Movahedian B, Razavi M, Movahedian A, Moeini M. Assessment of manifestations of temporomandibular Joint involvement in rheumatoid arthritis patients. J Isfahan Dent Sch 2006; 2(3): 35-40.

[16] Márton K. Oral symptoms of immunologic disorders. Part I. Systemic autoimmune diseases. Fogorv Sz 2003; 96(1): 9-15. [PMID: 12666389]

[17] Pawelczyk-Madalińska M, Sadlak-Nowicka J, Miernik-Kunc W. Clinical image of oral mucous membrane in rheumatoid arthritis patients. Przegl Lek 2006; 63(5): 253-6.

[PMID: 17036499]

[18] Kasper DL, Braunwald E, Fauci AS, Hauser SL, Longo DL, Jameson JL. Harrison's Principles of Internal Medicine. $16^{\text {th }}$ ed. McGraw-Hill 2005; p. 1973.

[19] Welbury RR, Thomason JM, Fitzgerald JL, Steen IN, Marshall NJ, Foster HE. Increased prevalence of dental caries and poor oral hygiene in juvenile idiopathic arthritis. Rheumatology (Oxford) 2003; 42(12): 1445-51.

[http://dx.doi.org/10.1093/rheumatology/keg395] [PMID: 12810923]

[20] Pinho MdeN, Oliveira RD, Novaes AB Jr, Voltarelli JC. Relationship between periodontitis and rheumatoid arthritis and the effect of nonsurgical periodontal treatment. Braz Dent J 2009; 20(5): 355-64.

[http://dx.doi.org/10.1590/S0103-64402009000500001] [PMID: 20126902]

[21] Detert J, Pischon N, Burmester GR, Buttgereit F. The association between rheumatoid arthritis and periodontal disease. Arthritis Res Ther 2010; 12(5): 218

[http://dx.doi.org/10.1186/ar3106] [PMID: 21062513]

[22] Araujo VMA, Melo IM, Lima V. Relationship between periodontitis and rheumatoid arthritis: Review of the literature. Mediators Inflamm 2015; 2(5): 18-28.

[23] Gumus P, Buduneli E, Biyikoglu B, Aksu K, Sarak F. Gingival Crevicular Fluid, serum levels of receptor activator of nuclear factor$\mathrm{Kb}$ ligand,osteoprotegrin,and interlukin-17 in pationts with rheumatoid arthritis and osteoporosis and with periodontal disease. J Periodontol 2013; 84(11): 1627-37. [PMID: 23327689]

[24] Khatibi M, Najafizadeh R, Shamshyrgaran S, MoezziGhadim N. The prevalence of oral mucosal lesions and associated factors in 385 patients with rheumatoid arthritis in rheumatology clinics of Tehran University for a period of one year. Pajoohande 2014; 19(2): 112-8.

[25] Geterud A, Bake B, Bjelle A, Jonsson R, Sandberg N, Ejnell H Swallowing problems in rheumatoid arthritis. Acta Otolaryngol 1991; 111(6): 1153-61.

[http://dx.doi.org/10.3109/00016489109100771] [PMID: 1763639]

[26] Pedrazas CHS, Azevedo MNL, Torres SR. Oral events related to lowdose methotrexate in rheumatoid arthritis patients. Braz Oral Res 2010; 24(3): 368-73.

[http://dx.doi.org/10.1590/S1806-83242010000300018] [PMID: 20877977]

[27] Hessari H, Vehkalahti MM, Eghbal MJ, Murtomaa HT. Oral health among 35- to 44-year-old Iranians. Med Princ Pract 2007; 16(4): $280-5$

[http://dx.doi.org/10.1159/000102150] [PMID: 17541293]

[28] Aliko A, Alushi A, Tafaj A, Lela F. Oral mucosa involvement in rheumatoid arthritis, systemic lupus erythematosus and systemic sclerosis. Int Dent J 2010; 60(5): 353-8.

[PMID: 21141208]

[29] Pakpour AH, Hidarnia A, Hajizadeh E, Kumar S, Harrison AP. The status of dental caries and related factors in a sample of Iranian adolescents. Med Oral Patol Oral Cir Bucal 2011; 16(6): e822-7. [http://dx.doi.org/10.4317/medoral.17074] [PMID: 21196852]

[30] Kim IJ, Lee HS, Ju HJ, Na JY, Oh HW. A cross-sectional study on the association between vitamin D levels and caries in the permanent dentition of Korean children. BMC Oral Health 2018; 18(1): 43. [http://dx.doi.org/10.1186/s12903-018-0505-7] [PMID: 29534753]

[31] Bahramian A, Bahramian M, Mehdipour M, et al. Comparing vitamin $\mathrm{d}$ serum levels in patients with oral lichen planus and healthy subjects. J Dent (Shiraz) 2018; 19(3): 212-6. [PMID: 30175191]

C) 2020 Parvaei et al.

This is an open access article distributed under the terms of the Creative Commons Attribution 4.0 International Public License (CC-BY 4.0), a copy of which is available at: (https://creativecommons.org/licenses/by/4.0/legalcode). This license permits unrestricted use, distribution, and reproduction in any medium, provided the original author and source are credited. 